\title{
Prevalence and knowledge of risk factors for diabetes mellitus among secondary school teachers in Abakaliki Educational Zone, Nigeria
}

\author{
Azuogu $\mathrm{BN}^{1}$, Madubueze $\mathrm{UC}^{2}$, Una $\mathrm{AF}^{1}$, Okedo-Alex $\mathrm{IN}^{2}$ and Azuogu $\mathrm{Vc}^{3}$ \\ ${ }^{1}$ Department of Community Medicine, Ebonyi State University, Abakaliki, Nigeria \\ ${ }^{2}$ Department of Community Medicine, Federal Teaching Hospital, Abakaliki, Nigeria \\ ${ }^{3}$ Department of Nursing, Ebonyi State University, Abakaliki, Nigeria
}

Correspondence: bnazuogu@gmail.com Phone: +234 8035643185

\begin{abstract}
Background: Teachers play an important role in delivering health education to empower students with skills for healthy living pertinent to prevent the development of non-communicable diseases. The development of non-communicable disease like hypertension, diabetes, obesity and cancers is highly associated with modifiable lifestyle. This study was conducted to determine the prevalence of self-reported Diabetes Mellitus, knowledge of its risk factors as well as risk factors among secondary school teachers in Abakaliki, Ebonyi State.

Methods: A cross-sectional survey was conducted among 282 secondary school teachers selected through multistage sampling technique using a self-administered pre-tested questionnaire for data collection. Bivariate and multivariate analysis was done using Statistical Package for the Social Sciences version 21 to determine associations between sociodemographic variables and knowledge of the risk factors for diabetes mellitus.

Results: The prevalence of self-reported diabetes mellitus among the teachers was 3.5\%. The knowledge of Diabetes Mellitus was generally poor as about $60 \%$ of respondents were categorized as having poor knowledge and $4.9 \%$ of them had glycosuria while majority 172 (61.0\%) reported family history of Diabetes Mellitus. More than half $(58.5 \%)$ reported not engaging in any form of physical exercise and more than half were considered overweight/obese. There was statistically significant relationship between family history and general knowledge of diabetes mellitus risk factors, $(P<0.001)$.

Conclusion: Knowledge of risk factors of diabetes mellitus was poor among the teachers, and there is urgent need for orientation towards routine screening for diabetes mellitus for this group of professionals who are strategic for education of teenagers.
\end{abstract}

Key words: Knowledge, Risk factors, Prevalence, Diabetes Mellitus.

Introduction

Diabetes Mellitus (DM) is among the four most common Non-communicable Diseases (NCDs) that contribute to a large number of adult morbidity and mortality. It is a growing public health concern in both developed and developing countries. ${ }^{-1,2}$ The World Health Organization (WHO) estimated that there are 425 million people afflicted with diabetes in the world, out of which more than 14 million reside in subSaharan Africa. It is predicted that by 2040 
this figure will be more than double. Nigeria is the most populated country in Africa and is home to over 5 million people living with DM. In 2015, Nigeria recorded more than 1.702 million cases of DM, with a $2.0 \%$ prevalence rate and 1,564.7 deaths amongst adults. ${ }^{3}$ Adequate knowledge of risk factors for diabetes is the first step towards effective preventive strategies to combat the disease burden in any population. The knowledge of DM risk factors is essential to make informed decision that will result in reduction in overall diabetes risk of an individual. Teachers represent the elite population in most communities in Nigeria and they constitute an important productive sector in the economy. They are also vested with the responsibility to impact knowledge on their students; hence they are an important target group for education of the general population.

A study done on diabetes mellitus' knowledge among self-reported diabetic teachers in Saudi Arabia showed inadequacy of knowledge; knowledge was poor on the general aspects of DM and about three- fourths were overweight and obese placing them at risk for diabetes. ${ }^{4} \mathrm{In}$ Nigeria, a recent study conducted in Sokoto, in the Northern part of the country showed that the prevalence of the risk factors for diabetes among teachers was high $(9.5 \%)$. For instance, obesity among the teachers was as high as $30.5 \%$ and sedentary lifestyle was $5.7 \%$. Another study conducted among teachers and other members of staff in a university community in Ile-Ife, Nigeria also reported low knowledge of diabetes, and high prevalence of its risk factors. ${ }^{6}$ Therefore, to carry out effective interventions to reduce the burden of diabetes and other NCDs it is important to assess the knowledge of the risk factors as well as the extent of the burden of diabetes in working class groups. Hence this study was carried out to assess the knowledge and prevalence risk factors for diabetes among this targeted group of people and to assess their self-reported prevalence of DM.

\section{Methods}

A descriptive cross-sectional study was conducted in Abakaliki Educational Zone of the 13 Local Government Areas (LGAs) of Ebonyi State. The secondary schools in the State are divided into three educational zones, namely: Abakaliki zone (4 LGAs), Onueke zone (4 LGAs) and Afikpo zone (5 LGAs). According to records obtained from the Planning, Research and Statistics Unit of Ebonyi State Secondary Education Board (SEB), there are 65 Government owned secondary schools in Abakaliki Educational zone distributed as follows: Abakaliki LGA has 9, Ebonyi LGA has 11, Izzi LGA has 16, and Ohaukwu LGA has 29. Abakaliki zone employs 1,182 teachers, out of which 728 are males and 454 are females. Multistage sampling technique was used; in the first stage one zone was balloted from the three educational zones by simple random method and in the second stage one school was balloted from a list of all the schools in each of the 4 LGAs of Abakaliki zone. Systematic random sampling method was used in the third stage to select a total of 282 teachers. The nominal roll of each school was used as a sampling frame and proportionate allocation was done to select the teachers.

The sample size of 282 was calculated using the Cochrane formula, ${ }^{7}$ adding to it a correction factor. Using a proportion of $50 \%$ for the target population, $95 \%$ confidence level at $\mathrm{p} \leq 0.05$ was considered statistically significant. The WHO recommended prevalence for calculation of sample size was applied to get a larger 
sample size for a more robust study as other percentages seen in literatures gave a smaller sample size. Only male and female teachers who were full time workers at the secondary schools were included in the study. A semi-structured self-administered pre-tested questionnaire was used to collect data from the teachers that gave consent to participate in the study and data was analysed using IBM SPSS version 21. Nine questions were constructed and used to elicit the knowledge of the DM risk factors from the teachers. Each correctly answered question was awarded 1 point with which percentage knowledge was calculated. The percentage knowledge score was then categorized into poor $(<50 \%)$, fair $(50-74 \%)$ and good knowledge $(\geq 75 \%)$. The results were presented on frequency tables and binary logistic regression was done to ascertain predictors of DM risk factors. Ethical clearance was obtained the research and ethics committee of Ebonyi State University, and permission was obtained from the SEB, while verbal informed consent was given by the participants.

\section{Results}

The teachers were predominantly females $(67.0 \%)$ with age range, $22-58$ years and majority (45.4\%) in 31-40 years age group. Two hundred and eighteen (77.3\%) respondents had ever married while $(99.3 \%)$ of them were Christians. The graduates constituted a greater proportion $(51.8 \%)$, followed by those who had NCE/Diploma (37.2\%). Respondents were mostly Igbos (94.3\%) and majority $(82.3 \%)$ resided within the urban area of the State.

Table 1 shows that all the respondents were aware of DM. Majority (59.9\%) had poor general knowledge of the risk factors for DM, while only about $21 \%$ had good knowledge and $18.9 \%$ had excellent knowledge of the risk factors of DM. Table 2 revealed $3.5 \%$ self-reported prevalence of DM among the respondents. Similarly, examinations of the respondents' urine showed that $4.9 \%$ had glucose in their urine. In Table 3, only gender had a statistically significant relationship with knowledge of the risk factors $(P=0.04)$. However, greater proportion of female teachers $(22.9 \%)$ had excellent knowledge compared to their male counterparts $(10.8 \%)$. Conversely, higher proportion of the males $(63.4 \%)$, had poor knowledge as against $58.2 \%$ females who had that level of knowledge. Within the age groups, greatest proportion of teachers who had excellent knowledge of the risk factors was seen among those aged 31-40 years $(21.9 \%)$, and those aged 51-60 years were least knowledgeable.

Table 4 revealed statistically significant relationships between family history of DM and general knowledge of DM risk factors among the teachers $(p<0.001)$ and between alcohol consumption and knowledge of DM risk factors $(\mathrm{p}=0.03)$. The proportion of respondents who had excellent knowledge was greater among those who had BMI in the range classified as obesity $(24.6 \%)$, while proportion of poor DM risk factor knowledge was commonest among those within underweight range (87.6\%). Poor knowledge was seen more in teachers who do not engage in physical exercise $(75.5 \%)$ and those who do not take fruits $(66.7 \%)$. Table 5 shows a binary logistic regression model table for predictors of knowledge of DM risk factors. Respondents who have family history of DM are about 20 times more likely to be more knowledgeable about DM risk factors compared to those without family history $(p<0.001)$, while those who consume alcohol are about two and half times more likely to have a better knowledge of the risk factors compared to their counterparts who do not take the beverage. 
Table 1: Awareness and knowledge of diabetes risk factors among the respondents

\begin{tabular}{lc}
\hline Variables & $\mathbf{n = 2 8 2}$ \\
Freq. $(\%)$
\end{tabular}

Table 2: Prevalence of self-reported DM and its risk factors among respondents Variables Freq. (\%)

Respondents who have DM

Yes

No

Total

Glycosuria $(\mathbf{N}=\mathbf{2 0 3})$

Yes

No

Total
$10(3.5)$

272(96.5)

282

10(4.9)

193(95.1)

203 
Table 3: Relationship between knowledge of risk factors of diabetes mellitus and sociodemographic characteristics of respondents $(n=282)$

\begin{tabular}{|c|c|c|c|c|c|}
\hline Variables & $\begin{array}{c}\text { Poor } \\
\text { knowledge } \\
\text { Freq. (\%) }\end{array}$ & $\begin{array}{c}\text { Good } \\
\text { knowledge } \\
\text { Freq.(\%) }\end{array}$ & $\begin{array}{l}\text { Excellent } \\
\text { knowledge } \\
\text { Freq. (\%) }\end{array}$ & DF & $\mathbf{X}^{2}(p-$ value $)$ \\
\hline \multicolumn{6}{|l|}{$\overline{\text { Age (years) }}$} \\
\hline $21-30$ & $54(60.7)$ & 17 (19.) & $16(20.2)$ & 6 & $3.99(0.68)^{*}$ \\
\hline $31-40$ & $72(56.2)$ & $28(21.9)$ & $28(21.9)$ & & \\
\hline $41-50$ & $36(65.5)$ & $13(23.5)$ & $6(10.9)$ & & \\
\hline $51-60$ & $7(70.0)$ & $2(20.0)$ & $1(10.0)$ & & \\
\hline \multicolumn{6}{|l|}{ Sex } \\
\hline Male & $59(63.4)$ & $24(25.8)$ & $10(10.8)$ & 2 & $6.39(0.04)$ \\
\hline Female & $110(58.2)$ & $35(19.0)$ & $43(22.9)$ & & \\
\hline \multicolumn{6}{|l|}{ Marital status } \\
\hline Never married & $44(68.8)$ & $14(21.9)$ & $6(9.4)$ & 2 & $4.10(0.08)$ \\
\hline Ever married & $125(57.3)$ & $46(21.1)$ & $47(21.6)$ & & \\
\hline \multicolumn{6}{|l|}{ Religion } \\
\hline Christianity & $168(60.0)$ & $60(21,4)$ & $52(18.6)$ & 2 & $1.51(0.39)^{*}$ \\
\hline Muslim & $1(50.0)$ & $0(0.0)$ & $1(50.0)$ & 2 & \\
\hline \multicolumn{6}{|l|}{ Education level } \\
\hline Secondary/TC2 & $10(52.6)$ & $5(26.3)$ & $4(21.1)$ & 6 & $2.88(0.84)^{*}$ \\
\hline NCE/Diploma & $63(60.0)$ & $20(19.0)$ & $22(21.0)$ & & \\
\hline Graduate & $87(59.6)$ & $34(23.3)$ & $25(17.1)$ & & \\
\hline Post graduate & $9(75.0)$ & $1(8.3)$ & $2(18.8)$ & & \\
\hline \multicolumn{6}{|l|}{ Place of residence } \\
\hline Urban & $136(58.6)$ & $50(21.6)$ & $46(19.8)$ & 2 & $1.16(0.61)^{*}$ \\
\hline Rural & $33(66.0)$ & $10(20.0)$ & $7(14.0)$ & & \\
\hline \multicolumn{6}{|l|}{ Ethnicity } \\
\hline Igbo & $160(60.2)$ & $57(21.4)$ & 49 (18.4) & 2 & $0.44(0.88)^{*}$ \\
\hline Others & $9(56.3)$ & $3(18.8)$ & $4(25.0)$ & & \\
\hline
\end{tabular}

*Fisher's exact test 
Table 4: Relationship between knowledge of risk factors and presence of risk factors for diabetes mellitus among the respondent $(n=282)$

\begin{tabular}{|c|c|c|c|c|c|}
\hline Variables & $\begin{array}{c}\text { Poor } \\
\text { Knowledge } \\
\text { Freq. }(\%) \\
\end{array}$ & $\begin{array}{c}\text { Good } \\
\text { Knowledge } \\
\text { Freq. }(\%) \\
\end{array}$ & $\begin{array}{l}\text { Excellent } \\
\text { knowledg e } \\
\text { Freq.(\%) }\end{array}$ & & df $X^{2}(p$-value $)$ \\
\hline \multicolumn{6}{|c|}{ Positive family } \\
\hline No & $101(91.8)$ & $8(7.3)$ & $1(0.9)$ & 2 & $77.92(<0.001)$ \\
\hline Yes & $68(59.5)$ & $52(30.2)$ & $52(30.2)$ & & \\
\hline \multicolumn{6}{|l|}{ BMI } \\
\hline Underweight & 7 (87.6) & $1(12.5)$ & $0(0.0)$ & 6 & $7.57(0.31)^{*}$ \\
\hline Normal & $58(61.1)$ & $22(23.2)$ & $15(15.8)$ & & \\
\hline Overweight & $45(61.6)$ & $12(16.4)$ & $16(21.9)$ & & \\
\hline Obese & $32(49.2)$ & $17(26.2)$ & $16(24.6)$ & & \\
\hline \multicolumn{6}{|c|}{$\begin{array}{l}\text { Engages in } \\
\text { physical exercise }\end{array}$} \\
\hline Yes & $185(57.0)$ & $53(22.4)$ & $49(20.7)$ & 2 & $5.6(0.5)^{*}$ \\
\hline No & $34(75.5)$ & $7(15.6)$ & $4(8.9)$ & & \\
\hline \multicolumn{6}{|c|}{ Consumes Vegetable } \\
\hline Yes & $166(59.9)$ & $59(21.3)$ & $52(18.8)$ & 2 & $0.36(1.00)^{*}$ \\
\hline No & $3(60.0)$ & $1(20.0)$ & $1(20.0)$ & & \\
\hline \multicolumn{6}{|c|}{ Consumes Fruits } \\
\hline Yes & $165(59.8)$ & $58(21.0)$ & $53(19.2)$ & 2 & $1.38(0.53)^{*}$ \\
\hline No & $4(66.7)$ & $2(33.3)$ & $0(0.0)$ & & \\
\hline \multicolumn{6}{|c|}{ Consumes Alcohol } \\
\hline Yes & $51(53.7)$ & $29(30.5)$ & $15(15.8)$ & 2 & $7.38(0.03)$ \\
\hline No & $118(63.1)$ & $31(16.6)$ & $38(20.3)$ & & \\
\hline \multicolumn{6}{|c|}{ Known DM patient } \\
\hline Yes & $6(60.0)$ & $2(20.0)$ & $2(20.0)$ & 2 & $0.02(1.0)^{*}$ \\
\hline No & $163(58.9)$ & $58(21.3)$ & $51(18.8)$ & & \\
\hline
\end{tabular}

*Fisher's exact test

Table 5: Logistic regression for predictors of DM risk factor knowledge among the respondents

\begin{tabular}{lcccc}
\hline Variables & $\begin{array}{c}\text { Wald statistics } \\
\left(\mathbf{X}^{2}\right)\end{array}$ & df & p-value & AOR (CI) \\
\hline Sex(Male) & 0.032 & 1 & 0.86 & $1.07(0.50-2.30)$ \\
Marital status (Never married) & 0.58 & 1 & 0.45 & $0.74(0.35-1.60)$ \\
Family history of DM (Yes) & 55.05 & 1 & $<0.001$ & $20.17(9.12-44.6)$ \\
Takes alcohol (Yes) & 5.00 & 1 & 0.01 & $2.40(1.20-5.00)$ \\
\hline
\end{tabular}

\section{Discussion}

This study assessed the knowledge of risk factors for DM and the prevalence of selfreported risk factors for the illness among teachers in Nigeria. Though all the respondents were aware of diabetes mellitus, $60 \%$ of them had poor knowledge of its risk factors. This is in contrast to other studies which found that over $60 \%$ of the respondents correctly identified the risk factors for $\mathrm{DM}^{8}{ }^{8-10}$ However, two of these studies were conducted among university staff that may be more exposed to information on diabetes than the secondary school teachers in our study. Nonetheless, the study among general 
population showed higher knowledge of diabetic risk factors than that seen among the teachers in our study. Other studies among diabetic and non-diabetic teachers have also reported limited knowledge on diabetes mellitus similar to our findings. ${ }^{4,11}$ This inadequate knowledge is worrisome and highlights the need for more awareness creation among these teachers who ought to educate the young minds on risk reduction practices pertinent to prevention of DM.

Concerning risk factors, $61.0 \%$ of the respondents had positive family history of DM. This is in conformity with findings from other similar studies where over $65 \%$ of the respondents reported having a positive family history of diabetes mellitus and another study on hypertension where $63 \%$ had positive family history., ${ }^{4,12}$ More than half of the respondents $(57.3 \%)$ were overweight and obese. This is similar to findings from other studies where majority of the teachers surveyed were overweight/obese. ${ }^{4,14}$ Also, majority of our respondents (98\%) reported that they consume fruits and vegetables, and this corresponds to findings from a study carried out in Pakistan. ${ }^{15}$ Lack of engagement in any form of physical exercise by majority $(58.5 \%)$ of our respondents is in contrast to a study in India where higher proportion of teachers $(80 \%)$ engaged in physical activity. $1^{4}$ Although this difference could be due to socio-economic development where roads are constructed with pedestrian lanes to encourage physical activities as opposed to the environment where our study was carried out.

Self-reported prevalence of previously diagnosed DM was $3.5 \%$. This is lower than the prevalence of $5.7-7 \%$ with fasting blood sugar reported from other studies done in South Africa and Nigeria. ${ }^{16,17}$
However, our assessment of prevalence of DM was self-reported and thus explains the lower estimates than that found in those studies. Gender was found to be significantly associated with knowledge of the risk factors for diabetes, with more females exhibiting better knowledge than their male counterparts. This is inconsistent with findings from other similar studies among teachers and nondiabetic patients, ${ }^{15,18}$ and there are no such relationship between gender and knowledge documented from other studies but this could be due to the fact that women are more inquisitive about lifestyle and health issues. ${ }^{19}$ Having a family history of DM and alcohol intake were significant predictors of good knowledge about DM. This is similar to findings from other studies..$^{-0,14,18}$ In addition, educational level, older age, being diabetic, and income level were significantly associated with knowledge of diabetes in those studies

\section{Conclusion}

The findings of this study showed a low self-reported prevalence of DM and a poor knowledge level of its risk factors among the teachers surveyed. Although majority of the teachers had normal blood pressure levels, most of them were overweight/obese. This study highlights the need for educational programs on risk factors and risk reduction practices among secondary school teachers in order to properly prepare them to act as role models and influencers on the minds of the growing school children they tutor.

\section{References}

1. Asif M. The prevention and control the type-2 diabetes by changing lifestyle and dietary pattern. J Educ Health Promot. Wolters Kluwer Medknow Publications; 2014;3:1.

2. Mathers CD, Loncar D. Projections of Global Mortality and Burden of 
Disease from 2002 to 2030. Samet J, editor. PLoS Med. Public Library of Science; 2006 ;3(11):442.

3. IDF African members. International Diabetes Federation. Available from: https://www.idf.org/ournetwork/regionsmembers/africa/members/20nigeria.htm Accessed on 15 August, 2018

4. Abahussain NA, El-Zubier AG. Diabetes knowledge among self reported diabetic female teachers: Al-khobar, Saudi Arabia. J Family Community Med. 2005;12(1):438. 5. Awosan KJ, Ibrahim MTO, Sabir AA, Ejimodu P. Awareness and prevalence of risk factors of coronary heart disease among teachers and bankers in Sokoto, Nigeria. J Med Med Sci. 2013;4(9):337-342

6. Erhun W, Olayiwola G, Agbani E, Omotoso N. Prevalence of hypertension in a University Community in South West Nigeria. African J Biomed Res. Bioline for the Ibadan Biomedical Communications Group; 2006;8(1):159.

7. Onwasigwe C. Principle \& Methods of Epidemiology. 2nd Edition. Enugu:EL'DEMK, 2010:147-148, 339-340.

8. Mbuya F, Fredrick F, Kundi B. Knowledge of diabetes and hypertension among members of teaching staff of higher learning institutions in Dar es Salaam, Tanzania. Tanzan J Health Res. 2014;16(2):17.

9. Faronbi JO, Oladepo RO, Faronbi GO, Olaogun AA. Blood Pressure Monitoring Practices and Health Seeking Behaviours among University Staff in Nigeria. Int J Caring Sci. 2014;7:5865.

10. Pongmesa T, Li S, Wee H. A Survey of Knowledge on Diabetes in the Central Region of Thailand. Int Soc Pharmacoeconomics Outcomes Res. 2009;12(3):110113.
11. Aycan Z, Bilgili H, Nur H, Kendirci P. Assessment of the Knowledge of Diabetes of the Managing Diabetes at School Program. J Clin Res Pediatr En docrinol. 2012;4(4):199203.

12. Salem SS, Al-rwaili MG, Alabdan NS. Awareness regarding diabetes mellitus risk factors and preventive measures among Saudi adult population in Riyadh. J Nurs Heal Sci. 2017;6(6):2531.

13. Sadeq R, Lafta RK. Knowledge, attitude and practice about hypertension in hypertensive patients attending hospitals in Baghdad, Iraq. South East Asia J Public Heal. 2017:7(1):2934.

14. Monica SJ, John S, Madhanagopal R. Lifestyle Determinants of Hypertension among Female School Teachers. Int J Life Sci. 2017;5(4):697702.

15. Nighat N, Iftikhar AK, Majid HQ, Syed AS. Knowledge and Risk assessment of diabetes mellitus at primary care level. A Preventive approach required combating the disease in a developing country. Pakistan J Med Sci. 2008;25(5):66772.

16. Balde NM, Camara A, Diallo AA, Kake A, Alpha M. Prevalence and awareness of diabetes in Guinea : findings from a WHO STEPS. J Endocrinol Metab Diabetes South Africa. 2017;22(3):36-42

17. Gezawa ID, Puepet FH, Mubi BM, Uloko AE, Bakki B, Talle MA, et al. Socio-demographic and Anthropometric risk factors for Type 2 diabetes in Maiduguri, NorthEastern Nigeria. Sahel Med J. 2015;18(1): 17 .

18. Almehmad RM, Abdullatif S, Qadir B, Taweel KM. Awareness of School Teachers about Diabetes Mellitus. Egypt J Hosp Med. 2018;70(7):12303.

19. Sasikala C, Palanisamy S, Rajenthina S, Nagashekhara M. Assessment of Knowledge of Diabetes Mellitus in the Urban Areas of Klang District, Malaysia. Pharmacy. 2017;5(11):18. 